\title{
Calibration of Dolomite Clumped Isotope Thermometry
}

\author{
Ian Z. Winkelstern ${ }^{1}$, Stephen Kaczmarek ${ }^{2}$, Kyger C Lohmann ${ }^{1}$, and John Humphrey ${ }^{3}$ \\ ${ }^{1}$ University of Michigan, Ann Arbor, USA \\ ${ }^{2}$ Western Michigan University, Kalamazoo, USA \\ ${ }^{3}$ Colorado School of Mines, Golden, USA \\ Email: ianzw@umich.edu
}

Differences between dolomite and calcite clumped isotope calibrations have yet to be resolved empirically across a range of temperatures. Acid fractionation differences calculated by Guo et al. (2009) suggest that dolomite $\Delta_{47}$ values should be $\sim 0.02 \%$ lower than calcites formed at the same temperature. Empirical calibrations for siderite (Fernandez et al. 2014) and apatite (Eagle et al. 2010), however, suggest that a universal $\Delta_{47}$ - temperature relationship may exist across all carbonate-bearing mineral phases.

We analyzed five synthetic and four natural dolomites formed at known temperatures. Synthetic dolomites were grown in $\mathrm{Mg}$-Ca-Cl solutions at temperatures of $200-235{ }^{\circ} \mathrm{C}$. Natural samples are constrained by fluid inclusion analyses $\left(\sim 90{ }^{\circ} \mathrm{C}\right)$, tropical climate $(\sim 25$ and $\left.\sim 27^{\circ} \mathrm{C}\right)$, and ocean water column depth $\left(\sim 3^{\circ} \mathrm{C}\right)$.

These data result in a calibration line that is statistically indistinguishable from the high acid reaction temperature calibration of Defliese et al. (2015). At least with current measurement capabilities, we find no evidence for a consistent dolomite $\Delta_{47}$ offset. We also found no evidence for a relationship between the degree of dolomite cation ordering and $\Delta_{47}$. These results further support the idea of a universal calibration for carbonate clumped isotope thermometry and enable new investigations into conditions of dolomite formation.

Defliese et al. (2015) Compositional and temperature effects of phosphoric acid fractionation on $\Delta_{47}$ analysis and implications for discrepant calibrations. Chemical Geology, 396, 51-60.

Eagle et al. (2010) Body temperatures of modern and extinct vertebrates from ${ }^{13} \mathrm{C}-{ }^{18} \mathrm{O}$ bond abundances in bioapatite. PNAS, 107, 10377-10382.

Fernandez et al. (2014) Siderite 'clumped isotope' thermometry: A new paleoclimate proxy for humid continental environments. 126, 411-421.

Guo, W., et al. (2009) Isotopic fractionations associated with phosphoric acid digestion of carbonate minerals: Insights from first-principles theoretical modeling and clumped isotope measurements. Geochimica et Cosmochimica Acta, 73, 7203-7225. 